\title{
Effects of Dopamine Depletion on Striatal Neurotensin: Biochemical and Immunohistochemical Studies
}

\author{
Andrew J. Bean, Matthew J. During, Ariel Y. Deutch, and Robert H. Roth \\ Departments of Pharmacology and Psychiatry, Yale University School of Medicine, New Haven, Connecticut 06510
}

Interactions between striatal dopamine (DA) and neurotensin (NT) have been suggested by anatomical, behavioral, and biochemical studies. Nigrostriatal DA neurons, in contrast to mesocorticolimbic DA neurons, do not appear to contain NT. Thus, distinct neuronal elements subserve interactions between DA and NT within the striatum. We have previously demonstrated that reserpine-induced depletion of striatal DA is accompanied by a dose- and time-dependent increase in striatal NT concentrations. In order to further characterize the effects of reserpine and to define the mechanism by which reserpine acts to increase striatal NT concentrations, we have used immunohistochemical and biochemical approaches. Immunohistochemical examination of rats pretreated with reserpine revealed marked increases in the density of NT-like immunoreactive (NT-li) perikarya and fibers, and the development of NT-li patches. Pretreatment with reserpine had no apparent effect on NT synthesis, as assessed by examination of cycloheximide-induced inhibition of protein synthesis. However, reserpine administration resulted in a significant decrease in the release of both DA and NT into the striatal extracellular fluid, as measured by in vivo microdialysis. These data suggest that the increase in striatal NT concentrations observed after reserpine treatment results from decreased release, rather than increased synthesis of the peptide.

Neurotensin (NT) is a tridecapeptide originally isolated from bovine hypothalamus (Carraway and Leeman, 1973, 1976) which is heterogeneously distributed through the CNS (Carraway and Leeman, 1976; Uhl et al., 1977; Jennes et al., 1982; Uhl, 1982). The demonstration that NT perikarya, fibcrs, and receptors exist within the striatum (Young and Kuhar, 1981; Jennes et al., 1982; Uhl et al., 1982), a brain region known to contain high concentrations of dopamine (DA), has led to studies aimed at elucidating the possible interactions between these transmitters/ modulators in this brain region. Nigrostriatal DA system function is influenced by NT. For example, NT enhances both basal

\footnotetext{
Received Feb. 10, 1989; revised Apr. 27, 1989; accepted June 1, 1989.

This work was supported in part by NIGMS-GM 07324, MH-14092, The Scottish Rite Schizophrenia Research Program, and The Department of Psychiatry, Yale University School of Medicine, and the Ribicoff Research Facilities, Connecticut Mental Health Center, State of Connecticut Department of Mental Health. M.J.D. is the recipient of an International Fogarty Fellowship.

We wish to thank Dr. Lothar Jennes for supplies of NT antiserum and Dr. Clinton Kilts for sharing unpublished data.

Correspondence should be addressed to Dr. R. H. Roth; Department of Pharmacology, Yale University School of Medicine, 333 Cedar Street, New Haven, CT 06510.

Copyright (C) 1989 Society for Neuroscience $0270-6474 / 89 / 124430-09 \$ 02.00 / 0$
}

and stimulated DA release from striatal slices; these effects may be mediated by NT receptors localized to the terminals of dopaminergic axons (De Quidt and Emson, 1983; Quirion et al., 1985; Hetier et al., 1988). Striatal NT levels have been shown to be influenced by DA; dopamine receptor antagonists have been reported to alter striatal NT levels and distribution (Govoni et al., 1980; Goedert et al., 1985; Frey et al., 1986; Nemeroff, 1986; Letter et al., 1987; Eggerman and Zahm, 1988).

We have recently demonstrated that reserpine, which depletes monoamines by disrupting their vesicular storage, produces a dose- and time-related increase in striatal NT concentrations (Bean et al., 1989). The influence of reserpine on striatal NT levels might be anticipated on the basis of a postulated tonic inhibitory influence of DA on striatal NT levels (Merchant et al., 1988a). The increase in striatal NT tissue concentrations resulting from treatment with either reserpine or DA receptor blockers is presumably due to increases in NT synthesis and/ or to decreases in NT release. In the present study, we have further characterized the increase in striatal NT produced by reserpine using immunohistochemical methods and have investigated the mechanism by which this increase is produced.

\section{Materials and Methods}

Animals. Male Sprague-Dawley rats (225-325 gm, Camm, Wayne, NJ) were used in all experiments. Rats were housed 2-3 per cage and were allowed free access to food and water at all times.

Experimental design. Immunohistochemical analysis of striatal NT was carried out following the procedure outlined below, 18-20 hr following the administration of reserpine $(5 \mathrm{mg} / \mathrm{kg}$, i.p.).

NT synthesis was estimated following the method of Frey et al. (1988). Briefly, rats were injected with cycloheximide $(1 \mathrm{mg} / \mathrm{kg}$, s.c.) followed $60 \mathrm{~min}$ later by $0.9 \%$ saline or reserpine $(5 \mathrm{mg} / \mathrm{kg}$, i.p.). Nineteen hours following cycloheximide injection, the rats were sacrificed by decapitation and the striatum was punch dissected as described previously (Bean et al., 1989). Samples were frozen at $-70^{\circ} \mathrm{C}$ until assayed for NT by radioimmunoassay (see below). Proteins were measured following the method of Lowry et al. (1951).

The effects of reserpine on NT and DA release in the rat striatum were determined by estimation of DA and NT content in the striatal extracellular fluid using in vivo microdialysis both before and after reserpine $(5 \mathrm{mg} / \mathrm{kg}$, i.p.) or $0.9 \%$ saline injections. We examined the release of DA and NT for $6 \mathrm{hr}$ following reserpine administration, a time at which a marked increase in NT and decrease in DA tissue concentrations occurs (Bean et al., 1989).

In vivo microdialysis. Dialysis probes were prepared as follows. Briefly, the probes were of concentric design using a hollow dialysis fiber ( $5000 \mathrm{MW}$ cutoff; Cuprophan, Hospal, Edison, NJ) sealed at one end with epoxy resin (Devcon, Danvers, MA). A length of hollow fused silica fiber (0.170 mm O.D., Anspec Inc., MI) was inserted into the dialysis tube to its end. The dialysis tubing containing the fused silica was then inserted through a length of 22 gauge stainless steel tubing into which another piece of fused silica tubing (outlet tube) had been placed. Both ends of the 22 gauge tubing were sealed with epoxy resin, leaving $4 \mathrm{~mm}$ of exposed dialysis tubing protruding from one end of 
the probe and the fused silica inlet and outlet tubes extending from the other end. A small piece of 23 gauge tubing was glued onto the end of the inlet tube connected to a length of PE-50 tubing, which was connected to a $1 \mathrm{ml}$ syringe mounted on a syringe pump (Harvard Instruments, S. Natick, MA). Artificial cerebrospinal fluid modified after Merlis (1940) [consisting of (in mM) NaCl, 135; $\mathrm{KCl}, 3.0 ; \mathrm{CaCl}_{2}, 1.2 ; \mathrm{MgCl}_{2}$, 1.0; phosphate, 2.0; and $100 \mu \mathrm{M}$ ascorbic acid, $\mathrm{pH}$ 7.4] was pumped through the dialysis probe at a rate of $2.1 \mu \mathrm{l} / \mathrm{min}$. At this flow rate the recovery of dopamine was between $10-20 \%$, while the recovery of NT was $2-8 \%$. In the reserpine experiment, samples collected during each 60 min period were divided such that a portion was used for HPLC analysis of dopamine content, while the remaining sample was frozen at $-70^{\circ} \mathrm{C}$ until assayed for NT content by radioimmunoassay.

In vivo dialysis experiments were accomplished following the placement of probes into the striatum of chloral hydrate anesthetized rats $(400 \mathrm{mg} / \mathrm{kg}$, i.p.) [coordinates: $\mathrm{AP}=+0.5, \mathrm{~L}=+2.5, \mathrm{~V}=-7.0$ (Paxinos and Watson, 1986)] and initiating perfusion. After a $120 \mathrm{~min}$ period for equilibration, samples were collected every $20 \mathrm{~min}$ (calcium experiment) or $60 \mathrm{~min}$ (reserpine experiment) for the duration of the experiment. Determination of a baseline was made by assaying samples for DA content (NT samples were assayed subsequently) and a stable measurement ( $\leq 20 \%$ variation in 3 consecutive samples) was typically obtained 60-100 min after sample collection was begun (i.e., 180-220 min following initiation of perfusion). The effect of calcium on NT release was determined by measuring the ability of potassium $(60 \mathrm{~mm}$, added to the artificial cerebrospinal fluid while altering the sodium concentration to maintain osmolarity) to elevate NT levels in the presence and absence of calcium in the artificial cerebrospinal fluid. We did not correct the level of NT or DA per sample for the recovery of the individual probe; thus, only relative changes in ECF concentrations are reported.

Radioimmunoassay of NT. The radioimmunoassay (RIA) for NT was performed under nonequilibrium conditions in $12 \times 75$ borosilicate tubes employing sodium phosphate buffer $(50 \mathrm{~mm}, \mathrm{pH} 7.4)$ containing $10 \mathrm{~mm}$ EDTA, $0.1 \%$ bovine serum albumin, and $0.02 \%$ sodium azide. The $500 \mu$ l reaction mixtures contained $100 \mu$ l of diluted primary antiserum raised in the rabbit (final dilution 1:250,000, which produced approximately $25 \%$ binding), $50 \mu \mathrm{l}$ of ${ }^{125} \mathrm{I}-\mathrm{NT}$ containing approximately $10,000 \mathrm{cpm}$, and $25 \mu \mathrm{l}$ of NT standard or unknown. To facilitate interassay comparisons, the standards for approximately 50 assays were aliquoted into sets of microcentrifuge tubes which were kept frozen at $-70^{\circ} \mathrm{C}$ until used in an assay. The assay was set up at room temperature by combining the standard or unknown, primary antibody, and buffer followed by vortex mixing. The tubes were then incubated at $4^{\circ} \mathrm{C}$ for $24 \mathrm{hr}$ at which time ${ }^{125} \mathrm{I}-\mathrm{NT}$ was added, followed by an additional 24 $\mathrm{hr}$ incubation period at $4^{\circ} \mathrm{C}$. Subsequently, the bound (B) and free (F) ${ }^{125}$ I-NT were separated using a goat anti-rabbit secondary antibody (Antibodies Inc., Davis, CA), which was incubated with the assay mixture for $4 \mathrm{hr}$, after which polyethylene glycol $(10 \%$ in $0.1 \mathrm{M}$ phosphate buffer) containing normal rabbit serum (Antibodies Inc., Davis, CA) was added. This was followed immediately by centrifugation for $15 \mathrm{~min}$ at $3000 \mathrm{rpm}$ in a refrigerated centrifuge (Beckman Instruments). The supernatant (free fraction) was decanted, and radioactivity in the pellet was counted. The $\mathrm{B} / \mathrm{F}$ ratios were corrected for nonspecific binding, which was estimated by examination of the $\mathrm{B} / \mathrm{F}$ ratio in the absence of antibody. Nonspecific binding was typically $1-2 \%$ of total. The $\mathrm{IC}_{50}$ for synthetic NT was approximately $4 \mathrm{fmol}$, while the detection limit of the assay was 0.15 fmol. Intra- and interassay variation was 5 and $8 \%$, respectively $(n=20)$.

Chromatography of NT. NT was separated chromatographically using a HPLC system comprised of 2 Altex model 100A pumps, an Altex model 420 gradient programmer, and a Beckman model 163 variablewavelength UV detector set at $210 \mathrm{~nm}$. Samples were injected onto a C-18 column where elution was achieved with a linear gradient (15$40 \%, 1 \% / \mathrm{min}$ ) of $100 \%$ acetonitrile in $1 \mathrm{M}$ sodium phosphate buffer and a flow rate of $2 \mathrm{ml} / \mathrm{min}$. One minute fractions were collected, and their NT content was measured by radioimmunoassay. Synthetic NT standards were assayed under the same conditions.

Chromatography of DA. DA concentrations were measured according to the technique of Church and Justice (1987) with minor modifications. Briefly, $20 \mu \mathrm{l}$ dialysate or standard was injected onto a $3 \mu \mathrm{m}$ narrowbore $\mathrm{C}-18$ column $(10 \times 2.1 \mathrm{~mm})$. Selective retention of DA was achieved with a mobile phase consisting of $0.05 \mathrm{~m}$ sodium phosphate buffer $(\mathrm{pH}$ 5.8) with $0.1 \mathrm{~mm}$ EDTA, $2.2 \mathrm{~mm}$ sodium octyl sulfate, $5 \mathrm{~mm}$ triethylamine, and $15 \%$ methanol at a flow rate of $0.35 \mathrm{ml} / \mathrm{min}$. Electrochemical detection was accomplished using an LC-3 amperometric detector

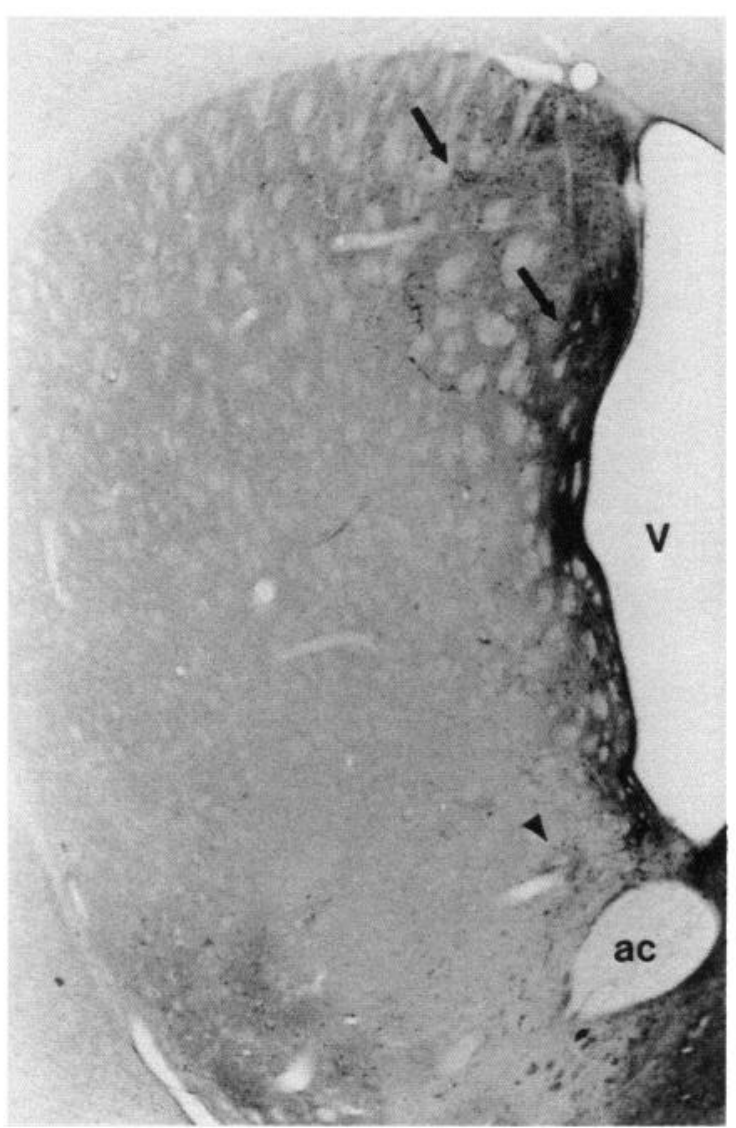

Figure 1. Striatal NT-li following pretreatment with colchicine. NTli fibers are present in high density in the periventricular striatum. Some NT-li perikarya can be seen in the dorsal striatum and in the periventricular as well as subcallosal regions (arrows). In the ventral striatum, NT-li patches which mainly consist of NT-li fibers can be seen (arrow$h e a d)$. $V$, ventricle; $a c$, anterior commissure.

(Bioanalytical Systems, West Lafayette, IN) with a glassy carbon electrode ( $+0.7 \mathrm{~V}$ vs. $\mathrm{Ag} / \mathrm{AgCl}$ reference). Chromatograms were recorded on a chart recorder and peak heights of unknowns were compared with standards for quantitation.

Immunohistochemistry. Rats used for immunohistochemistry received either $200 \mu \mathrm{g}$ colchicine into the lateral ventricle $24 \mathrm{hr}$ prior to sacrifice or $5 \mathrm{mg} / \mathrm{kg}$ (i.p.) reserpine 18-20 hr before sacrifice (reserpinetreated rats did not receive colchicine). Animals were deeply anesthetized with chloral hydrate $(600 \mathrm{mg} / \mathrm{kg}$, i.p.) and were transcardially perfused using a modification of the $\mathrm{pH}$-shift method of Berod et al. (1981). Briefly, animals were perfused with normal saline at room temperature, followed by ice-cold $4 \%$ paraformaldehyde in $0.1 \mathrm{M}$ sodium acetate $(\mathrm{pH} 6.5)$, followed by $4 \%$ paraformaldehyde- $0.08 \%$ glutaraldehyde in $0.05 \mathrm{M}$ sodium borate (pH 9.5). Tissue was postfixed for 4$6 \mathrm{hr}$, transferred to $0.1 \mathrm{M}$ sodium phosphate buffer ( $\mathrm{pH} 7.4$ ), and coronal sections $(50 \mu \mathrm{m})$ cut on a vibrating microtome. Sections were then processed for immunohistochemistry using the avidin-biotin method. Free-floating sections were rinsed in $0.05 \mathrm{M}$ Tris-buffered saline (TBS) and subsequently incubated in methanolic-peroxide for $10 \mathrm{~min}$. Following repeated washes in TBS, tissue was incubated in TBS containing $0.3 \%$ Triton X-100 and $2 \%$ normal serum (TBS + ) for $60 \mathrm{~min}$. Sections were then incubated in the same NT antibody used for the radioimmunoassay (1:6000) for $48 \mathrm{hr}$. Sections were incubated in biotinylated secondary antibody for 90-120 min, washed with TBS, then incubated in the avidin solution (Vector Laboratories) for 60-90 min. Tissue sections were then developed in diaminobenzidine with hydrogen peroxide, washed in TBS, and mounted on slides before being dehydrated, cleared, and coverslipped.

Materials. The NT antiserum used in these studies was kindly donated by Dr. Lothar Jennes, Department of Anatomy, Wright State University 

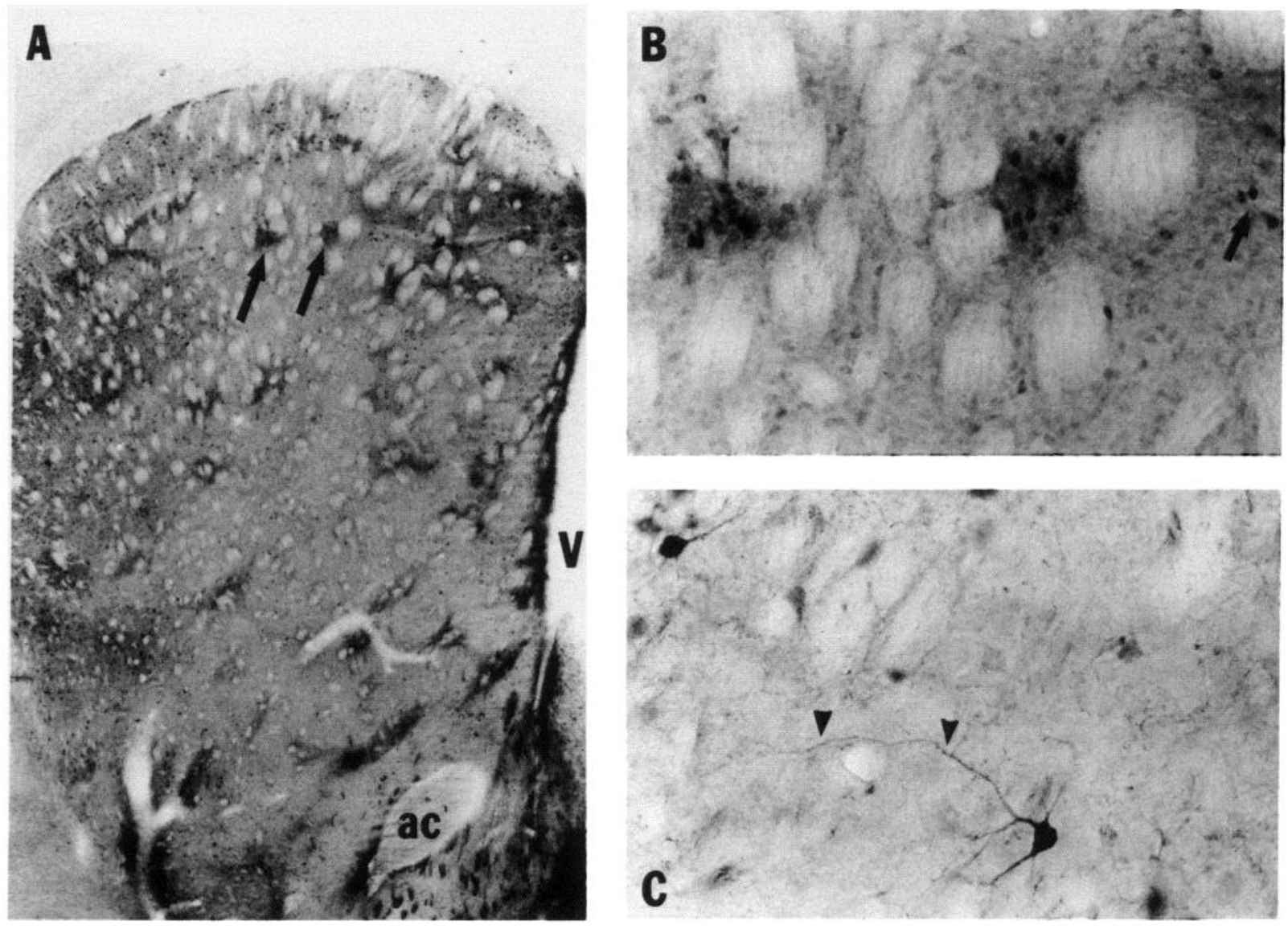

Figure 2. A, Localization of NT-li elements in the striatum of a reserpine-treated rat. NT-li fibers are organized into discrete patches (arrows) throughout both the dorsal and ventral striatum. NT-li perikarya are present both within and outside of the patches of high fiber density and are most prominent in the periphery of the striatum. B, Patches of NT-li fibers (marked by arrows in $A$ ). The patches of high fiber density also contain NT-li perikarya. However, cell bodies are also observed outside of the NT-li fiber patches (arrow). The NT-li perikarya outside of the fiber patches are frequently seen to be arranged in clusters. $C$, An example of an NT-li striatal neuron. This neuron has clearly defined processes (arrows) which extend for a considerable distance; however, most striatal NT-li neurons do not elaborately branch. $V$, ventricle; $a c$, anterior commissure.

School of Medicine, Dayton, OH. Synthetic NT and all NT fragments, as well as somatostatin and corticotropin-releasing factor (CRF) were purchased from Bachem Inc. (Torrance, $\mathrm{CA}$ ). Neuromedin $\mathrm{N}$ was purchased from Peninsula Labs (Belmont, CA). ${ }^{125}$ I-NT was purchased from Amersham Inc. (Arlington Heights, IL). Cycloheximide was purchased from Sigma (St. Louis, MO), and reserpine (Serpasil) was a gift of CibaGeigy Co. (Summit, NJ).

Statistics. The NT turnover experiments were analyzed by means of ANOVA with post hoc Dunnett's test, while the dialysis experiments were analyzed by ANOVA with repeated measures.

\section{Results}

\section{Immunohistochemistry}

Immunohistochemical examination of the striatum of rats pretreated with colchicine revealed the presence of moderately dense NT-like immunoreactive (NT-li) fibers in the medial subcallosal and periventricular regions (Fig. 1). In the precommissural striatum, the highest density of fibers was observed in the medial striatum and nucleus accumbens, while in the postcommissural striatum fiber labeling was concentrated mainly in the medial and dorsal regions. NT-li neurons were observed in the medial striatum and within the nucleus accumbens. Scattered NT-li neurons adjacent to the callosum were observed at all levels of the striatum (see Fig. 1).

The number of striatal NT-li neurons in rats pretreated with reserpine was markedly increased, as was the density of NT-li fibers (Fig. 2A). Both NT-li perikarya and fibers appeared to be present in discrete patches, surrounded by regions relatively devoid of immunoreactive elements (Fig. 2, $A-C$ ). The patches of NT-li neurons and fibers were prominent in the dorsal and lateral aspects of the striatum and in the ventromedial striatum, including the nucleus accumbens; the central core of the precommissural striatum contained few patches of NT-li fibers and cells.

\section{NT synthesis}

A modification of the techniques of Frey et al. (1988) and Bannon and Goedert (1984) was used to determine whether the reserpine-induced increase in striatal NT levels was attributable to an increase in peptide synthesis. An increase in tissue NT levels was observed following reserpine administration (see Fig. 3). Following administration of the protein synthesis inhibitor cycloheximide, NT levels were significantly decreased from control levels (Fig. 3). However, when cycloheximide was administered in addition to reserpine, levels of NT observed in the striatum were significantly increased versus those seen following control and cycloheximide treatments, but did not differ significantly from the increased levels seen after reserpine alone. 


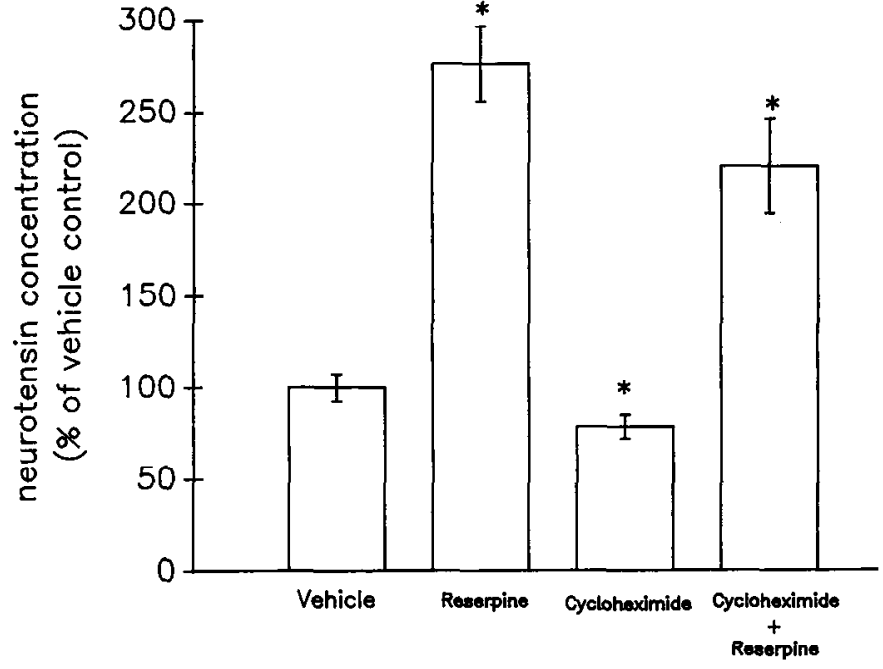

Figure 3. Effects of reserpine on NT synthesis. Reserpine $(5 \mathrm{mg} / \mathrm{kg}$, i.p.) was administered $18 \mathrm{hr}$ prior to sacrifice. Cycloheximide $(1 \mathrm{mg} /$ kg, i.p.) was administered $19 \mathrm{hr}$ prior to sacrifice, i.e., $1 \mathrm{hr}$ prior to reserpine or vehicle. Basal NT concentrations in the striatum were 30.0 $\pm 2.48 \mathrm{fmol} / \mathrm{mg}$ protein. Data are expressed as mean \pm SEM percentage of vehicle-injected controls $(n=8)$. Cycloheximide plus reserpine group did not differ significantly from reserpine group alone. ${ }^{*} p \leq 0.05$, relative to the vehicle control group.

\section{$D A$ and $N T$ measurements}

In order to determine whether reserpine altered striatal NT release, we developed and characterized a sensitive NT radioimmunoassay which was used in conjunction with brain microdialysis sampling techniques. A radioimmunoassay utilizing an antibody directed against the $\mathrm{COOH}$-terminal of the NT molecule was used to measure NT in the same striatal dialysis sample used for DA measurement. The specificity of this antibody for both the tridecapeptide, as well as fragments of the parent peptide, is illustrated in Table 1 (also see Jennes et al., 1982). As can be seen in Table 1, the COOH-terminal fragments NT (8-13) and NT (9-13) exhibited 51 and $68 \%$ cross-reactivity, respectively, with the full length peptide. However, the C-terminally related peptide neuromedin $\mathrm{N}$ and amino terminal fragments NT (1-11) and NT (1-8) cross-reacted less than $0.1 \%$ with NT. Furthermore, neither somatostatin, a peptide of similar molecular weight to NT, or CRF was observed to crossreact $(<0.1 \%)$ with the antibody.

To characterize the material collected through the dialysis probe as authentic NT, dialysis samples were separated by HPLC, and eluted fractions were assayed using our radioimmunoassay. Elution profiles of fractions were compared with that of synthetic NT. HPLC analysis revealed an absorbance peak in the dialysis sample which coeluted with synthetic NT (Fig. 4). Furthermore, when fractions of HPLC eluate were measured by RIA, the major NT-li peak from the dialysis sample occurred at the same time point as the peak containing synthetic NT (Fig. 5).

We quantified the DA found in our dialysis samples by comparison with DA standards assayed according to the same meth-

Figure 4. HPLC analysis of striatal dialysate for the presence of NT. Synthetic standards and dialysis samples (see Materials and Methods) were separated with reverse-phase HPLC using a linear gradient of 15-
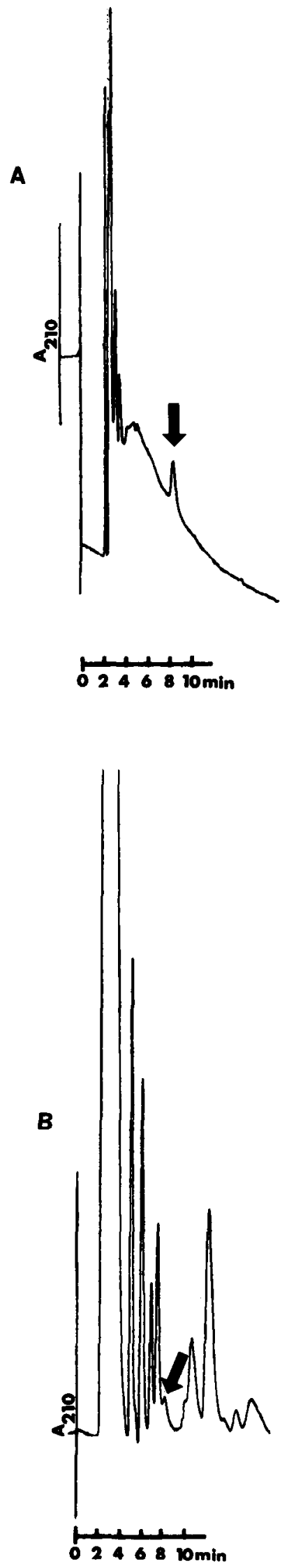

$40 \%$ acetonitrile in $0.1 \mathrm{M}$ phosphate buffer, and UV detection at 210 nm. $A$, Synthetic NT standard; $B$, dialysis sample. Arrows refer to NT signal in $A$ and $B$. 
odology (HPLC-EC). Characterization of the DA peak in the chromatographs was accomplished by both modification of the analytical (HPLC-EC) method (altering the buffer and determining the profile of the dialysis sample in relation to a standard) and by determining the response to pharmacological manipulation. $\alpha$-Methyl-para-tyrosine, apomorphine, and reserpine all decreased the size of the peak which coeluted with DA standards with magnitudes and time courses comparable to those observed previously (data not shown, see Fig. 7; Zetterstrom and Ungerstedt, 1984; Butcher et al., 1988). Furthermore, amphetamine and electrical stimulation of the median forebrain bundle both increased the size of the peak which coeluted with DA standards as measured by HPLC-EC (data not shown; Zetterstrom et al., 1983; Imperato and DiChiara, 1984; Butcher et al., 1988).

\section{In vivo Microdialysis}

We have examined the dependence of the release of NT on calcium. As can be seen in Figure 6, substitution of $60 \mathrm{mM}$ potassium for an equal amount of sodium in the artificial cerebrospinal fluid resulted in an elevation of NT levels (epoch 4). However, when calcium was omitted from the artificial cerebrospinal fluid, potassium did not evoke an increase in NT levels significantly different from baseline (Fig. 6, epoch 7). Following characterization of the dialysate for the presence of DA and NT and the calcium dependence of such release, studies on the effects of reserpine were begun. Basal DA and NT values in the striatal dialysate were $2.47 \pm 0.16$ and $0.040 \pm 0.004 \mathrm{fmol} /$ min, respectively. Reserpine administration produced decreases in both DA and NT concentration in the extracellular fluid (ECF; Fig. 7). The magnitude of the decline in DA at its nadir was $79.0 \pm 4.9 \%(p \leq 0.05$ at all points after reserpine), while the maximal decline in NT levels was $77.2 \pm 5.0 \%(p \leq 0.05$ at all points except $180 \mathrm{~min}$ ).

\section{Discussion}

The present data suggest that the reserpine-induced increase in NT levels may be attributable to a decrease in peptide release rather than an increase in NT synthesis. Moreover, the increase in striatal NT levels was paralleled by an increase in the density of NT-li neurons and fibers, including the emergence of a patchy organization of NT-li elements. Thus, the reserpine-induced decrease in release of NT appeared to elevate intraneuronal concentrations of the peptide.

In order to test the hypothesis that increases in striatal NT produced by reserpine are due to alterations in NT release, we developed an in vivo microdialysis method coupled with sensitive RIA and HPLC-EC analytical assays. While the measurement of femtomole quantities of DA has been accomplished

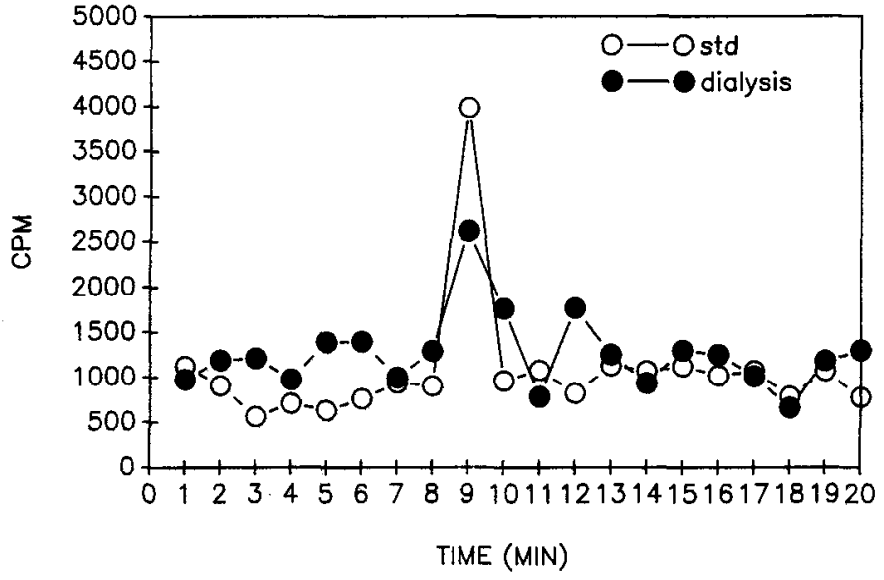

Figure 5. Analysis of NT-li in fractions of HPLC-separated NT standard and dialysis samples. One minute fractions of HPLC eluate were collected from the HPLC on which a standard NT solution and dialysis samples were separated. The fractions were quantitated using our RIA (see Materials and Methods), and data are expressed as radioactivity (cpm) per sample.

by many laboratories (Ungerstedt and Hallstrom, 1987), the measurement of dialyzed peptides from brain has proven to be more difficult. Using a nonequilibrium RIA, the sensitivity limit of our assay is approximately $0.15 \mathrm{fmol}$ NT. We were therefore able to divide 20 min samples and measure both DA and NT within such samples. The NT antibody used appears to bind to the COOH-terminal region of the NT molecule (based on the cross-reactivity profile of various NT fragments, Table 1), consistent with the previous immunohistochemical characterization by Jennes et al. (1982). It is interesting to note that the antibody recognizes neuromedin $\mathrm{N}$, a COOH-terminally related peptide which is encoded by the rat NT gene (Kislauskis et al., $1988)$, to a limited degree $(<0.1 \%)$, while the $\mathrm{COOH}$-terminal fragments NT (8-13) and NT (9-13) are recognized nearly to the same degree as the parent tridecapeptide. These data may suggest that the 3-dimensional conformation of neuromedin $\mathrm{N}$ restricts its ability to bind to sites which accept NT.

In the present study, microdialysis was used to monitor the release of both DA and NT within the same sample of striatal dialysate in response to reserpine administration. Such in vivo microdialysis allows a more physiological study of the regulation of peptide release than do studies which are done in vitro. Following reserpine administration, a decline in both DA and NT levels in the striatal ECF was observed (Fig. 7). The present data suggest that the decline in NT concentrations may occur secondary to the decrease in DA release; this speculation is

Table 1. Comparison of the cross-reactivities of various NT-related peptides

\begin{tabular}{lll} 
Compound & Structure & $\begin{array}{l}\text { Cross- } \\
\text { reactivity } \\
(\%)\end{array}$ \\
\hline NT & pGlu-Leu-Tyr-Glu-Asn-Lys-Pro-Arg-Arg-Pro-Tyr-Ile-Leu-OH & 100 \\
NT (1-11) & pGlu-Leu-Tyr-Glu-Asn-Lys-Pro-Arg-Arg-Pro-Tyr-OH & $<0.1$ \\
NT (1-8) & pGlu-Leu-Tyr-Glu-Asn-Lys-Pro-Arg-OH & $<0.1$ \\
NT (8-13) & H2N-Arg-Arg-Pro-Tyr-Ile-Leu-OH & 51 \\
NT (9-13) & H2N-Arg-Pro-Tyr-Ile-Leu-OH & 68 \\
Neuromedin N & H2N-Lys-Ile-Pro-Tyr-Ile-Leu-OH & $<0.1$ \\
\hline
\end{tabular}




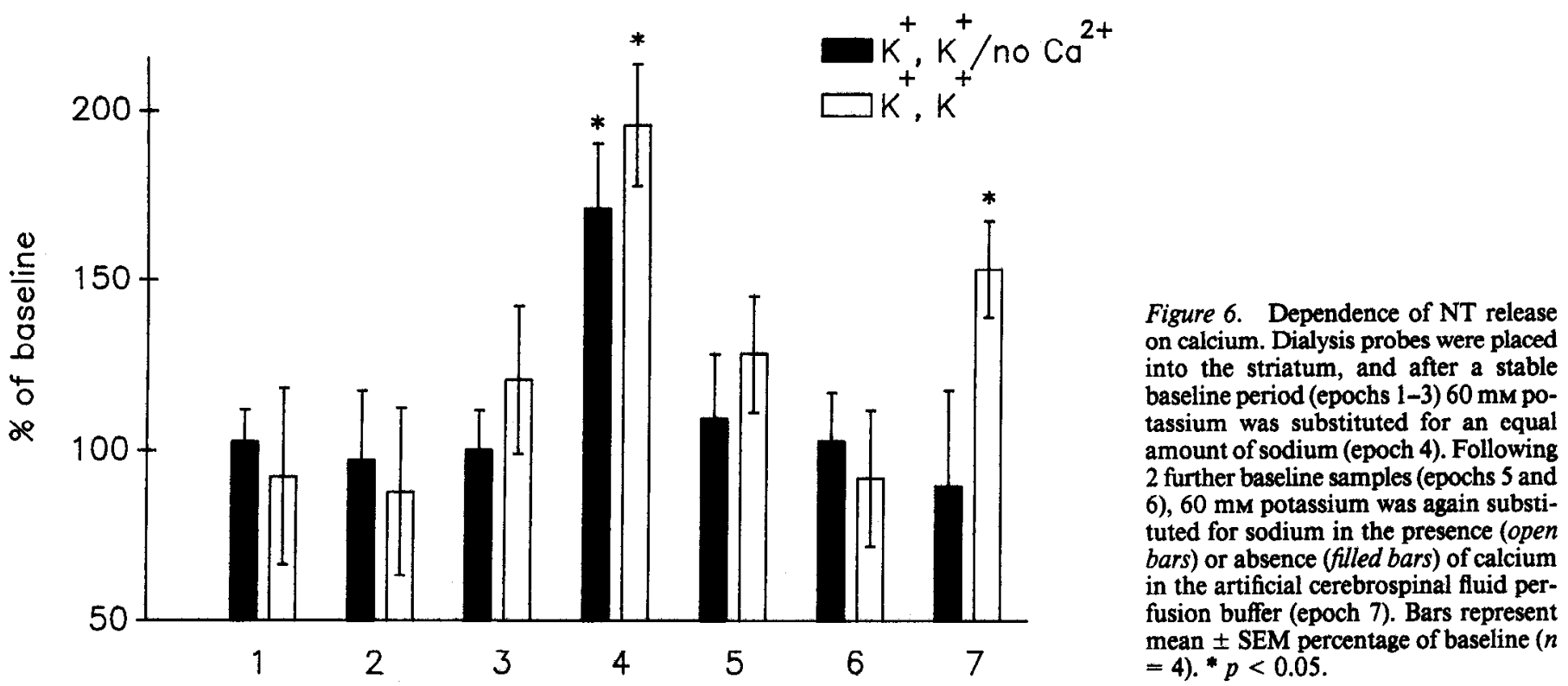

supported by the anatomical findings in the present report and by our previous biochemical data (Bean et al., 1989).

The approaches used to study the turnover of nonpeptide transmitters, such as inhibition of specific synthesizing or degrading enzymes, would not be appropriate for the estimation of peptide turnover because of the differences in the modes of synthesis and degradation of these 2 classes of neuroactive substances. NT levels were examined after cycloheximide-induced inhibition of protein synthesis in order to assess NT synthesis. This method has been used previously to examine the effects of haloperidol on substance $P$ and NT synthesis (Bannon and Goedert, 1984; Frey et al., 1988). The lack of selectivity of cycloheximide for the synthesis of particular proteins could be potentially confounding if, for example, one neuropeptide modulates the synthesis of another. However, the turnover of other peptides, such as substance $P$, estimated using the cycloheximide method agrees well with other indirect measures of their turnover (Bannon and Goedert, 1984). In the present study, cycloheximide pretreatment had no significant effect on reserpineinduced elevation of striatal tissue levels of NT (Fig. 3). These



Figure 7. DA and NT release following reserpine or vehicle administration. Dialysis probes were placed into the striatum of chloral hydrate-anesthetized rats. Following establishment of a stable baseline for DA release (insert), either reserpine $(5 \mathrm{mg} / \mathrm{kg}$, i.p.) or vehicle was administered and samples were collected subsequently for $6 \mathrm{hr}$. Baseline DA levels were $2.47 \pm 0.16$ $\mathrm{fmol} / \mathrm{min}$, while NT levels were 0.040 $\pm 0.004 \mathrm{fmol} / \mathrm{min}$. $\nabla$, time of vehicle or drug injection. ${ }^{*} p<0.05$. 
data are therefore consistent with the observations of Frey et al. (1988), who noted that haloperidol pretreatment did not alter NT turnover. Thus, lowering the synaptic efficacy of DA, either through blocking DA receptors or inducing DA depletion, does not appear to alter striatal NT synthesis.

Using immunohistochemical techniques we have observed that the reserpine-induced increase in striatal NT levels corresponds to an increase in the apparent density of striatal NT-li perikarya and fibers (Fig. 2), suggesting an increase in intraneuronal stores of the peptide. These data may explain why striatal NT levels, as measured by RIA, are moderately high, yet it is difficult to demonstrate striatal NT-li with immunohistochemistry (even after colchicine pretreatment, see Fig. 1). Furthermore, these data may suggest that under normal circumstances NT may be released from striatal neurons at such a rapid rate as to prevent the accumulation of sufficient peptide in either the cell body or neuronal processes to be visualized using immunohistochemical methods. Thus, the inhibition of neuronal NT release by reserpine and the resultant accumulation of NT within neurons may allow a more representative estimate of the actual density of striatal NT neurons and fibers.

NT-li perikarya were observed in the striata of animals treated with reserpine, even though these animals did not receive intraventricular colchicine. The presence of a large number of striatal NT-li cell bodies was observed in every animal treated with reserpine, in contrast to the relative lack of striatal NT-li neurons (except for the medial periventricular stria) in animals subjected only to intraventricular colchicine. It is difficult to compare the distributions of NT-li fiber staining in the striata of animals treated with reserpine and those receiving only colchicine pretreatment since colchicine frequently reduces fiber and terminal staining. While it would be desirable to compare more fully the characteristics of NT-li fiber and terminal staining in animals treated with colchicine with those treated with reserpine and colchicine, the latter treatment is invariably fatal. However, the critical difference between the 2 conditions is simply that striatal NT-li perikarya become apparent only under conditions of reduced dopaminergic tone (such as that elicited by reserpine treatment) and are not seen when they are pretreated even with large doses of colchicine (up to $250 \mu \mathrm{g}$ intraventricularly).

The striatum is organized into histochemically defined compartments in which some efferent and afferent striatal pathways begin or terminate (Olson et al., 1972; Fuxe et al., 1979; Graybiel, 1984; Gerfen et al., 1987). In this context, it was intriguing to note that the increase in density of striatal NT-li following reserpine treatment was accompanied by the appearance of patches of NT-li fibers (Fig. 2). These patches of dense NT-li fibers also contained perikarya and were found in both the dorsal and ventral striatum. The NT-li patches were surrounded by areas relatively devoid of NT-li fibers, although some peptide perikarya were present. Previous histochemical observations by Zahm and coworkers (Zahm, 1987; Eggerman and Zahm, 1988; Zahm and Heimer, 1988), Goedert et al. (1983), and Sugimoto and Mizuno (1987) have described the compartmentalization of ventral striatal NT-li into clusters; these striatal NT-li patches appear to correspond to zones which are acetylcholinesterase poor and opiate receptor rich. Our data confirm the presence of NT-li patches in the ventral striatum and extend these observations to the dorsal striatum, a region in which only scattered NT-li neurons have been observed previously (Jennes et al., 1982; Uhl et al., 1982; Goedert et al., 1983; Zahm and

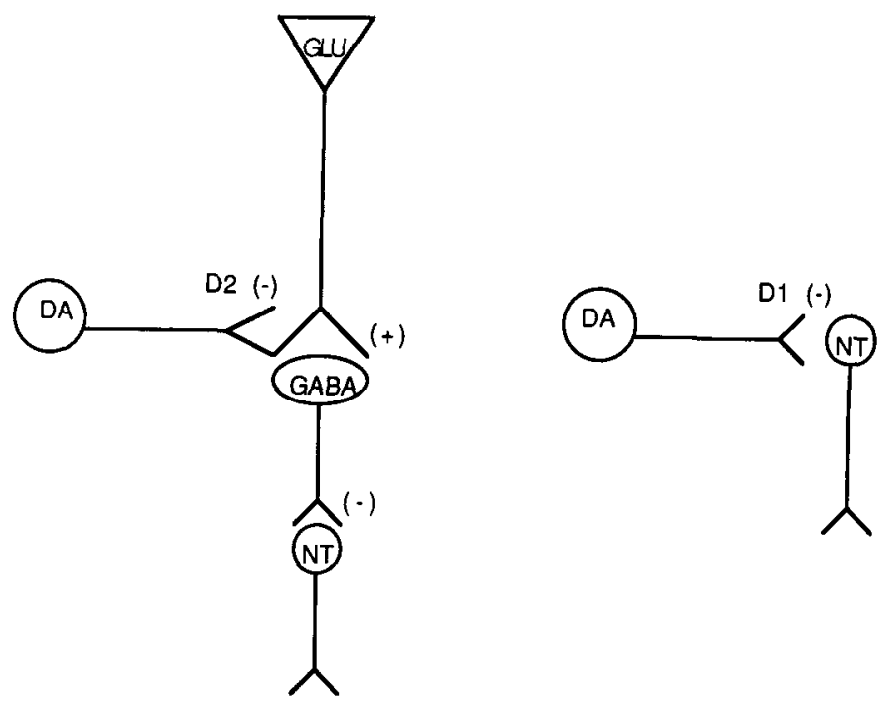

Figure 8. Theoretical synaptic arrangement which may underlie striatal DA-NT interactions. For discussion, see text.

Heimer, 1988). Additional study is required to define the dorsal striatal NT patches in terms of other previously defined neurochemical markers and in order to begin to understand how to define NT with respect to the overall striatal infrastructure.

Recent data concerning the alteration of striatal NT concentrations by antipsychotic agents has prompted renewed examination of the interactions of striatal DA and NT (Nemeroff, 1986). The ability of acute administration of both typical and atypical antipsychotic agents to increase striatal NT levels is consistent with our observations on reserpine. Reserpine is indeed an effective antipsychotic agent (Slotkin, 1974) and thus the similarities between reserpine and the modern antipsychotic agents are interesting and suggest a common effect of these drugs on striatal NT. However, the implications of these data for antipsychotic efficacy or side effects are not yet clear.

Several lines of evidence support the hypothesis that DA may modulate the release of striatal NT. Anatomical studies have shown that dopaminergic axons terminate on the dendrites and cell bodies of medium spiny striatal cells; among striatal medium spiny cells are those containing GABA or NT (Ribak et al., 1979; Sugimoto and Mizuno, 1987). Pharmacological studies have shown that administration of D2 antagonists increase, while D2 agonists decrease, striatal NT concentrations. Conversely, D1 antagonists decrease and D1 agonists increase striatal NT tissue levels (Frey et al., 1986; Letter et al., 1987). The distinct regulatory roles of D1 and D2 receptors on striatal NT neurons suggest certain ways through which DA transmission may influence the release of NT from striatal neurons.

A working model of striatal DA-NT interactions which takes into account previous anatomical and biochemical data as well as the present data can be envisioned (Fig. 8). Thus, reduction of the synaptic efficacy of DA by blockade of $\mathrm{D} 2$ receptors may initiate the following sequence of events (refer to Fig. 8): (1) a loss of the inhibition exerted by DA on excitatory corticostriatal afferents. This may occur by a direct effect on D2 receptors located on corticostriatal neurons (Brown et al., 1983; Mercuri et al., 1985; Filloux et al., 1988). Alternatively, DA afferents synapse onto the shafts of dendritic spines, thereby inhibiting the glutamatergic input which arrives onto spine heads (Freund et al., 1984). This would lead to (2) an increase in the influence 
of excitatory corticostriatal afferents onto inhibitory GABAergic interneurons (Cospito and Kultas-Llinsky, 1981), effecting (3) inhibition of the activity of NT cells, which in turn would result in (4) a decrease in NT release into the ECF and (5) an increase in tissue levels of NT. Conversely, blockade of D1 receptors may be envisioned to release the inhibitory influence of DA on NT cells directly (Mercuri et al., 1985; Calabresi et al., 1987; $\mathrm{Hu}$ and Wang, 1988), leading to an increase in their activity; this would produce an increase in NT release, and therefore a decrease in tissue levels, consistent with previous data (Frey et al., 1986; Letter et al., 1987). The effects of reserpine (present study) on striatal NT appear to be more similar to the increase in striatal NT levels evoked following D2 blockade, possibly indicating a predominance of D2 tone on striatal NT neurons. Additionally, the effects of D1 and D2 agonist treatment are consistent with the increase (D1) and decrease (D2) in NT tissue levels predicted by this model (Merchant et al., 1988b). Although alternative mechanisms can be envisioned, this theoretical scheme may serve as a convenient model and generate appropriate empirical studies designed to test the hypothesis.

In the present study, we have examined the effect of reserpineinduced DA depletion on striatal NT. The data herein suggest that DA depletion produces a decrease in NT release, resulting in the increase in striatal tissue levels of NT, as well as the apparent increase in striatal NT-li as measured by immunohistochemistry. We have proposed a working model which takes into account the dissimilar ways in which DA, through D1 and D2 receptors, produces inhibition of striatal neurons. Such an arrangement may provide a framework with which to examine (either at the receptor level or at the level of signal transduction systems) the mechanisms that enable differential sensitivity of striatal NT neurons to occur following acute and chronic treatment with selective D1 and D2 receptor blockers, effects which may be related to some effects of antipsychotic drugs (Frey et al., 1986; Nemeroff, 1986).

\section{References}

Bannon, M. J., and M. Goedert (1984) Changes in substance P concentrations after protein synthesis inhibition provide an index of substance P utilization. Brain Res. 301: 184-186.

Bean, A. J., T. E. Adrian, I. M. Modlin, and R. H. Roth (1989) Dopamine and neurotensin storage in colocalized and noncolocalized neuronal populations. J. Pharmacol. Exp. Ther. 249: 681-687.

Berod, A., B. K. Hartman, and J. F. Pujol (1981) Importance of fixation in immunohistochemistry: Use of formaldehyde solutions at variable pH for the localization of tyrosine hydroxylase. J. Histochem. Cytochem. 29: 844-850.

Brown, J. R., and G. W. Arbuthnott (1983) The electrophysiology of dopamine (D2) receptors: A study of the actions of dopamine on corticostriatal transmission. Neuroscience 10:349-355.

Butcher, S. P., I. S. Fairbrother, J. S. Kelly, and G. W. Arbuthnott (1988) Amphetamine-induced dopamine release in the rat striatum: An in vivo microdialysis study. J. Neurochem. 50: 346-355.

Calabresi, P., N. Mercuri, P. Stanzione, A. Stefani, and G. Bernardi (1987) Intracellular studies on the dopamine-induced firing inhibition of neostriatal neurons in vitro: Evidence for D1 receptor involvement. Neuroscience 20: 757-771.

Carraway, R., and S. E. Leeman (1973) The isolation of a new hypotensive peptide, neurotensin, from bovine hypothalami. J. Biol. Chem. 248: 6854-6861.

Carraway, R., and S. E. Leeman (1976) Characterization of radioimmunoassayable neurotensin in the rat. J. Biol. Chem. 251: 7045-7052.

Church, W. H., and J. B. Justice, Jr. (1987) Rapid sampling and determination of extracellular dopamine in vivo. Anal. Chem. 59: 712-716.
Cospito, J. A., and K. Kultas-Llinsky (1981) Synaptic organization of motor corticostriatal projections in the rat. Exp. Neurol. 72: 257266.

De Quidt, M., and P. C. Emson (1983) Neurotensin facilitates dopamine release in vitro from rat striatal slices. Brain Res. 274: 376380.

Eggerman, K. W., and D. S. Zahm (1988) Numbers of neurotensinimmunoreactive neurons selectively increased in rat ventral striatum following acute haloperidol administration. Neuropeptides 11: 125132.

Filloux, F., T. H. Liu, C. Y. Hsu, M. A. Hunt, and J. K. Wamsley (1988) Selective cortical infarction reduces [3H]sulpiride binding in rat caudate-putamen: Autoradiographic evidence for presynaptic D2 receptors on corticostriate terminals. Synapse 2: 521-531.

Freund, T. F., J. F. Powell, and A. D. Smith (1984) Tyrosine hydroxylase-immunoreactive boutons in synaptic contact with identified striatonigral neurons with particular reference to dendritic spines. Neuroscience 13: 1189-1215.

Frey, P., K. Fuxe, P. Eneroth, and L. F. Agnati (1986) Effects of acute and long-term treatment with neuroleptics on regional telencephalic neurotensin levels in the male rat. Neurochem. Int. 8: 429-434.

Frey, P., M. Lis, and D. M. Coward (1988) Neurotensin concentrations in rat striatum and nucleus accumbens: Further study on their regulation. Neurochem. Int. 12: 33-38.

Fuxe, K., K. Andersson, R. Schwarcz, M. Perez de la Mora, T. Hökfelt, M. Ferland, and R. Tapia (1979) Studies on different types of dopamine nerve terminals in the forebrain and their possible interactions with hormones and with neurons containing GABA, glutamate, and opioid peptides. Adv. Neurol. 24: 197-215.

Gerfen, C. R., M. Herkenham, and J. Thibault (1987) The neostriatal mosaic: II. Patch- and matrix-directed mesostriatal dopaminergic and nondopaminergic systems. J. Neurosci. 7: 3915-3934.

Goedert, M., R. W. Mantyh, S. P. Hunt, and P. C. Emson (1983) Mosaic distribution of neurotensin-like immunoreactivity in the cat striatum. Brain Res. 274: 176-179.

Goedert, M., S. D. Iversen, and P. C. Emson (1985) The effects of chronic neuroleptic treatment on neurotensin-like immunoreactivity in the rat central nervous system. Brain Res. 335: 334-336.

Govoni, S., J. S. Hong, H. Y. T. Yang, and E. Costa (1980) Increase of neurotensin content elicited by neuroleptics in nucleus accumbens. J. Pharmacol. Exp. Ther. 215: 413-417.

Graybiel, A. M. (1984) Correspondence between the dopamine islands and striosomes of the mammalian striatum. Neuroscience 13: 11571187.

Hetier, E., A. Boireau, P. Dubedat, and J. C. Blanchard (1988) Neurotensin effects on evoked release of dopamine in slices from striatum, nucleus accumbens, and prefrontal cortex in rat. Naunyn Schmiedeberg's Arch. Pharmacol. 337: 13-17.

$\mathrm{Hu}, \mathrm{X} .-\mathrm{T}$, and R. Y. Wang (1988) Comparison of effects of D-1 and D-2 dopamine receptor agonists on neurons in the rat caudate putamen: An electrophysiological study. J. Neurosci. 8: 4340-4348.

Imperato, A., and G. DiChiara (1984) Trans-striatal dialysis coupled to reverse phase high performance liquid chromatography with electrochemical detection: A new method for the study of the in vivo release of endogenous dopamine and metabolites. J. Neurosci. 4:966977.

Jennes, L., W. E. Stumpf, and P. W. Kalivas (1982) Neurotensin: Topographical distribution in rat brain by immunohistochemistry. J. Comp. Neurol. 210: 211-224.

Kislauskis, E., B. Bullock, S. McNeil, and P. R. Dobner (1988) The rat gene encoding neurotensin and neuromedin N: Structure, tissue specific expression, and evolution of exon sequences. J. Biol. Chem. 263: 4963-4968.

Letter, A. A., L. A. Matsuda, K. M. Merchant, J. W. Gibb, and G. R. Hanson (1987) Characterization of dopaminergic influence on striatal-nigral neurotensin systems. Brain Res. 422: 200-203.

Lindefors, N., E. Brodin, and U. Ungerstedt (1987) Microdialysis combined with a sensitive radioimmunoassay: $A$ technique for studying in vivo release of neuropeptides. J. Pharmacol. Methods 17:305312.

Lowry, O. H., N. J. Rosebrough, A. L. Farr, and R. J. Randall (1951) Protein measurement with the folin phenol reagent. J. Biol. Chem. 193: 265-275.

Merchant, K. M., L. Bush, J. W. Gibb, and G. R. Hanson (1988a) Receptor-specific interactions of the nigro-striatal dopamine projec- 
tions with striatal neurotensin systems in rat brain. Soc. Neurosci. Abstr. 14: 114.

Merchant, K. M., A. A. Letter, J. W. Gibb, and G. R. Hanson (1988b) Changes in the limbic neurotensin systems induced by dopaminergic drugs. Eur. J. Pharmacol. 153: 1-9.

Mercuri, N., G. Bernadi, P. Calabresi, A. Contugno, G. Levi, and P. Stanzione (1985) Dopamine decreases cell excitability in rat striatal neurons by pre- and postsynaptic mechanisms. Brain Res. 358: 110121.

Merlis, J. K. (1940) The influence of cerebrospinal fluid calcium on a spinal flexion reflex. Am. J. Physiol. 129: 422-423.

Nemeroff, C. B. (1986) The interaction of neurotensin with dopaminergic pathways in the central nervous system: Basic neurobiology and implications for the pathogenesis and treatment of schizophrenia. Psychoneuroendocrinology 11: 15-37.

Olson, L., A. Seiger, and K. Fuxe (1972) Heterogeneity of striatal and limbic dopamine innervation: Highly fluorescent islands in developing and adult rats. Brain Res. 44: 283-288.

Paxinos, G., and C. Watson (1986) The Rat Brain in Stereotaxic Coordinates, Academic, New York.

Quirion, R., C. C. Chiueh, H. D. Everist, and A. Pert (1985) Comparative localization of neurotensin receptors on nigrostriatal and mesolimbic dopaminergic terminals. Brain Res. 327: 385-389.

Ribak, C. E., J. E. Vaughn, and E. Roberts (1979) The GABA neurons and their axon terminals in rat corpus striatum as demonstrated by GAD immunohistochemistry. J. Comp. Neurol. 187: 261-284.

Slotkin, T. A. (1974) Reserpine. In Neuropoisons: Their Pathophysiological Actions, L. L. Simpson and D. R. Curtis, eds., pp. 1-60, Plenum, New York.

Sugimoto, T., and N. Mizuno (1987) Neurotensin in projection neu- rons of the striatum and nucleus accumbens, with particular reference to coexistence with enkephalin and GABA: An immunohistochemical study in the cat. J. Comp. Neurol. 257: 383-395.

Uhl, G. R. (1982) Distribution of neurotensin and its receptor in the central nervous system. Ann. NY Acad. Sci. 400: 132-149.

Uhl, G. R., M. J. Kuhar, and S. H. Snyder (1977) Neurotensin: Immunohistochemical localization in the rat central nervous system. Proc. Natl. Acad. Sci. USA 74: 4059-4063.

Ungerstedt, U., and A. Hallstrom (1987) In vivo microdialysis-A new approach to the analysis of neurotransmitters in the brain. Life Sci. 41: 861-864.

Young III, W. S., and M. J. Kuhar (1981) Neurotensin receptor localization by light microscopic autoradiography in rat brain. Brain Res. 206: 273-285.

Zahm, D. S. (1987) Concentration of neurotensin immunoreactive neurons in the ventral striatum of the rat: Ventromedial caudateputamen, nucleus accumbens, and olfactory tubercle. Neurosci. Lett. 81: 41-47.

Zahm, D. S., and L. Heimer (1988) Ventral striatopallidal parts of the basal ganglia in the rat: 1 . Neurochemical compartmentation as reflected by the distributions of neurotensin and substance P immunoreactivity. J. Comp. Neurol. 272: 516-535.

Zetterstrom, T., and U. Ungerstedt (1984) Effects of apomorphine on the in vivo release of dopamine and its metabolites, studied by brain dialysis. Eur. J. Pharmacol. 97: 29-36.

Zetterstrom, T., T. Sharp, C. A. Marsden, and U. Ungerstedt (1983) In vivo measurement of dopamine and its metabolites by intracerebral dialysis: Changes after d-amphetamine. J. Neurochem. 41: 17691773. 